\title{
Meaning in translation: A model based on translation shifts
}

\author{
Bruno Osimo \\ ISIT (Istituto Superiore Interpreti e Traduttori), Fondazione SCM, Milano
}

This paper proposes a model of meaning-based translation shifts. While the definition of 'meaning' may be problematic at best, in practice it is possible to observe what remains in the reception of a message after it has been translated. The author draws on the work of Leuven-Zwart and Torop to build a new model with seven shift categories, each one identified by its influence on various aspects of reception. Examples for each shift category are taken from the first book of the Bible. The findings are channelled into a model for translation meaning.

\section{Introduction: meaning as translation}

According to Yurij Lotman, a founder of the semiotics of culture, thinking is translation and translation is dialogue (Lotman 1990). If we consider the worldview of each individual as a (subjective) culture - as he does - and if we consider, different cultures to be different ways to 'metaphorize' perceived reality, then it follows that thinking consists in translating other cultures into one's own, and vice versa. For the same reason, dialogue consists of the constant translation between individual and group cultures. Such a view shifts the focus from linguistic to cultural differences which, in turn, include linguistic differences as well.

Charles Sanders Peirce, the founder of the science of signification, did not leave a corpus of texts, but rather fragments (Gorlée 2007), which are a virtually unending source for reflection on, among other things, the nature of meaning; and one of the most widespread definitions of 'meaning' coincides with the process of translation. According to Peirce, who as far as we know never had in mind interlingual or verbal translation, "the meaning of a sign is the sign it has to be translated into" (4:132). In order to explain the meaning of something I must use a message, either verbal or nonverbal; often this message is, broadly speaking, a metaphor. Said message is the meaning of the sign. Such view is a pragmatic, operative view of meaning, i.e. the meaning of something coincides with the practical consequences of that thing in a given culture (person, or group). "This conception of meaning [...] emphasizes the subjective and contextualized character of every meaning construction. [...] If meaning is also an objective, social construction, we should look for it in the collective; if meaning is, on the contrary, a subjective, context-dependent construction, we should look for it in the individual" (Cornejo 2007:246). 
From this perspective, meaning is conveyed partly by the intrinsic value of a sign and partly by the context (culture, in Lotmanian terms) in which it is decoded (and sometimes recoded). How much meaning is intrinsic in the sign and how much is conveyed by the receiving culture is a culturally specific matter. If we define 'delusion' as an over-interpretation (Eco 1992), i.e. an interpretation that is not sufficiently based on its given input, then how much 'sufficiently based' is cannot be universally defined: it is determined by how much over-interpretation is acceptable in a given culture.

The example of Chekhov's Sour cherry orchard may be helpful. The whole plot of the famous play is based on the fact that the fruits produced by the orchard trees are not cherries ('chereshni', prunus avium) but a sour, wild variety of cherry called 'vishnya' (prunus cerasus) which, being soft and delicate, are not marketable unless they are preserved in vases in the form of jam or confiture. However, all over the non-Russian world people are convinced that the plot is about cherries and thus they may not actually be aware of the reason why the noble family declines, which is, in fact, because they do not remember how to prepare sour cherries for sale. Since there is no receiving culture in which this mistranslation ('cherries' instead of 'sour cherries') was considered a mistake, we can say that this is a case in which a delusionary translation ('delusionary' because it negates the difference between a cherry and a sour cherry) is 'good enough', i.e. is 'sufficiently based' on its given input.

In the light of this definition, meaning cannot be absolute: as with the sense of a text in an interlingual translation, meaning must be actualized on a context-dependent, case-by-case basis, within the limits given by the receiving culture. "To 'understand' implies the historical contextualization of cultural/psychological phenomena in search of reason where these make sense. Methodologically, the search for reason involves also the appropriation of the socio-cultural conditions where the spiritual-psychic phenomenon takes place" (Cornejo 2007:247). The reference to the impossibility to ever provide an exact definition of meaning should not be considered an escape from the task to define it. Berkeley (1710-1734) wrote that "a word becomes general by being made the sign, not of an abstract general idea, but of several particular ideas, any one of which it indifferently suggests to the mind". If you accept this - and I do - then the individual component cannot be ignored.

As we can see, each portion in the metatext of a translation process (I prefer to use the Popovič's terminology (2007) in which originals are called 'prototexts' and translations 'metatexts') is not based on a single interpretation but on a whole set of interpreting acts, of ideas by the interpreter; they are based on the intrinsic meaning of a sign, and partly on the decoding context; and these interpretations are correlated, i.e. they are coherent one with another; more generally, meaning is based on a set of interpretants, on a set of subjective but motivated and correlated ideas. 'Interpretant' is meant here as an idea triggered by the perception of something (a sign). "A 
sign $[\ldots]$ is a vehicle conveying into the mind something from without. That for which it stands is called its object; that which it conveys, its meaning; and the idea to which it gives rise, its interpretant" (Peirce 3:339).

While the previous quotations seem to refer to single non-verbal signs only, the following may better clarify that verbal signs and sentences are meant, too: "The meaning of a proposition is itself a proposition. Indeed, it is no other than the very proposition of which it is the meaning: it is a translation of it" (Peirce 5:427). Therefore, meaning and object are two different things. Meaning is in the mind of an interpreter; an object may be concrete or abstract, but it tends to be outside the mind of the interpreter. In short, meaning in Peircean terms is based on interpretants, conveyed by a sign, and is itself a sign into which the prototext has to be translated. As in the famous Jakobsonian example of cheese (1959), translation is not about objects - it is about meanings.

This is why the interlingual verbal translation of a single prototext, working with meanings and not with objects, gives many different results (metatexts). As Peirce says, translation is

a method for ascertaining the real meaning of any concept, doctrine, proposition, word, or other sign. The object of a sign is one thing; its meaning is another. Its object is the thing or occasion, however indefinite, to which it is to be applied. Its meaning is the idea which it attaches to that object, whether by way of mere supposition, or as a command, or as an assertion (Peirce 5:6; quoted in this light in Gorlée 2007:216).

This has many implications. If we pass from the Stoic (better known as 'Saussurian') dual model (signans-signatum), characterized by recursiveness (if signans $\mathrm{A} \rightarrow$ signatum $\mathrm{A}$, then signatum $\mathrm{A} \rightarrow$ signans $\mathrm{A}$ ), to a triadic model such as (signans-translation-signatum) or (sign-interpretantobject) or (prototext-translatant-metatext), there is no recursiveness at all, and no way to go back to the beginning after the first translation process has taken place; there is no possibility to back-translate, so to speak. Adding a third component to the process is equivalent to accounting for human action (interpretation, translation) and, thus, imperfection, subjectivity, hence potential evolution of meaning in communication. "A (wo)man-made translation equivalent cannot, of course, be more than an idea, an almost fictive invention of the translator and the reader [...] This does not exclude the creation of private meaning" (Gorlée 2007:243). The model could be the following: if [signans $\mathrm{A} \rightarrow$ translation $\mathrm{X} \rightarrow$ signatum $\mathrm{A}$ ], then [signatum $\mathrm{A}$ $\rightarrow$ translation $\mathrm{Y} \rightarrow$ signans $\mathrm{B}$ ], then [signans $\mathrm{B} \rightarrow$ translation $\mathrm{Z} \rightarrow$ signatum C], etcetera. This would be a translation-oriented version of the unlimited-semiosis view (Eco 1984), according to which any interpretant, any object eventually becomes a sign in a further triad. This is how, according to Peirce, thoughts are born: 
And thus the intellectual character of beliefs at least [is] dependent upon the capability of the endless translation of sign into sign. An inference translates itself directly into a belief. A thought which is not capable of affecting belief in any way, obviously has no signification or intellectual value at all. If it does affect belief it is then translated from one sign to another as the belief itself is interpreted (Peirce $7: 357)$.

Therefore it is possible, in my opinion, to have a theory of translation based on the analogy between thought and translation. If we consider the 'third' pole, the one missing in the Stoic view, the pole of ideas, the pole of subjective filtering, it is easier to use Shannon and Weaver's mathematical model of communication (1949). According to this model, a message that reaches its destination has something more than the initial message (due to redundancy) and something less (due to loss). Every time we try to translate a text, the very fact of changing code, or changing wording, results in a different balance between message loss and redundancy, between said, unsaid and oversaid. The aim of translation cannot therefore be to create an equivalent metatext: it is to create a metatext that is different. The point is to create a metatext that is different in a way that is compatible with the target reader and with the dominant (in the Jakobsonian sense of main feature indispensible to (de)code a text) assigned to the text by the target culture, by the translator and by the translator's client.

Such a view sheds new light on the very notion of 'translation' (and 'communication'): translation (communication) is not about equivalence (mere conveyance of information); instead, it is about new meaning (information growth) and loss of meaning; in short, it is about information change. The new sign shares with its previous one an evolved part of the meaning, plus a loss. From this point of view, thoughts share the notion of 'evolution'. That is to say, a potential 'sign' that is not able to affect the perceiver's belief (a hypothetic dyadic, recursive, purely redundant 'sign') has no significance, i.e. it is not a sign. Jakobson was greatly fascinated by such an identification of meaning, translation, and evolution of knowledge.

One of the most felicitous, brilliant ideas which general linguistics and semiotics gained from [Peirce] is his definition of meaning as "the translation of a sign into another system of signs" (Jakobson 1975: 251).

A hypothetic 'translation' that is equivalent with respect to its original is not a translation: it is a copy (Lûdskanov 2008:XV-XVI). "A translator is far from a machine-like individual producing replicas, but possesses a flesh-and-blood mind that 'does, knows, says, believes, hopes for, rejects, denies, or supposes, even all that did, does, or might occur anywhere at any time"” (Gorlée 2007:248). 
Pym (2007) provides a thorough discussion of what he labels as natural and directional equivalence. He correctly explains that the notion of 'equivalence' is not to be demonized, because its critics are themselves using it all the time albeit in a different form. I completely agree with him. My point here, however, is different. My focus here is not on the equivalence of the translation process, but on the remaining part of it. Following Popovič's and Lûdskanov's models, we can state that a translation process, starting from a prototext, produces a metatext (i.e. a naturally or directionally 'equivalent' text, if you will) minus an involuntary, necessary loss, plus an involuntary, necessary added meaning. Since translating is a psychic process, such elements of lost and added meaning have a subjective component. "Methodologically, the fact that psychic life is always intentional means that every psychological act is personal and unique, so that the firstperson view is basic to adequately understand psychic life" (Cornejo 2007:247).

The fact that subjective and collective cultures are progressive obstacles (subcodes) to communication up to the point where national culture implies a change of code should not be underestimated. The contribution of each passage, as we have seen, does not imply only losses, but also gains. It is important, however, not to think only in terms of equivalence. Discussions limited to translation equivalence have hindered both translation studies and the research on meaning. The interpreter's mind changes the point of view from which a sign (or thought, for that matter) is seen, and this way it gives it new meaning, it shifts its significance. "How many fruitless discussions about mentalism and anti-mentalism would be avoided if one approached the notion of meaning in terms of translation, which no mentalist and no behaviorist could reject" (Jakobson 1975: 251). I propose to follow Jakobson's advice literally, and try to explore meaning starting from interlingual verbal translation shifts.

\section{The translation shift model}

To recapitulate, in the semiotic approach to translation, Popovič (1975) introduced the terms 'prototext' and 'metatext',for 'source text' and 'target text' respectively, and then widely employed in the semiotic studies of translation. In Popovič's view, the terms 'prototext' and 'metatext' apply not only to interlingual translation, but also to any other type of transformation, such as intertexts, summaries and so on. In this way, metatexts are always conceptually in the plural form, since you can get as many metatexts as types of translation processes as you can imagine and actualize. Since each metatext is produced by the subjective point of view of the individual translator in the single moment in which s/he produces it, the sum of the potential (and real) metatexts is the sum of the subjective points of view of a given prototext. In this sense culture is not collective, but a sum of subjectivities. 
The term 'shift' was introduced by Catford in 1965 and is used to indicate any difference in the text produced through translation as compared to the original. Popovič (1975:71) also used the notion of communication shift. Shifts can be seen from many points of view: shifts in the number or length of words used, shifts in semantic meaning, shifts in the effect produced by the translated text on the reader, shifts in the perception of the culture expressed by the text.

In order to focus on prototext-metatext shifts, some models analyze micro-structural shifts independent of the cultural context, and draw inferences concerning the whole text, or at least produce a list of micro-shifts concerning a specific prototext-metatext pair. On the other hand, chronotopic models - i.e. systemic models based on the particular meaning that words acquire in given contexts - aim to create a typology of potential (meta)texts, considered as whole texts. In this case, the shift categories are not absolute as above, but are relative to the cultural context of the given text (see Osimo 2004 for details).

An example of the former approach is van Leuven-Zwart's model (1989-90), which aims to describe micro-structural shifts deriving from the translator's conscious or unconscious choices on a semantic, syntactic or pragmatic level, and to classify them. This is a bottom-up model, i.e. there is no previous analysis of the text's poetics from which one may infer the specific keywords to be analyzed within a comparative framework.

Torop's chronotopic model (2000), on the other hand, begins by analyzing the text in view of its potential translations and, once the keywords have been identified in a systemic perspective (with reference to the specific text-system), the model studies the changes caused by shifts in the text's poetics. This is a top-down model, i.e. details are analyzed only after their systemic importance has been identified.

Since shifts are seen from the point of view of the reader's reception of the metatext, one of the main practical difficulties in chronotopic analysis, is connecting a category of perception shifts to concrete linguistic elements. A translation-oriented analysis, therefore, having identified the dominant and the subdominants of a given text, will identify their expression on the linguistic plane.

Both approaches have their advantages. The advantage of the former, bottom-up model is that one can also analyze the parts of the text that do not have any specific systemic importance; this is very important because shifts may (and do) occur there as well. The advantage of the latter, topdown model is that it immediately sheds light on the main text-specific elements, distinguishing them from the secondary ones. Without a chronotopic analysis, the decision concerning translation shifts addresses one element or another indifferently, regardless of their systemic value, neglecting the dominant and the subdominants (Osimo 2004:92-94). Therefore, a model combining both approaches is balanced: the top-down approach works with a typology of the possibilities of translation (the main types of translation, poetics of translation) and the bottom-up approach 
focuses on the translator's subjective choices, the translator's individual poetics. In this context we can talk about traditional and individual shifts.

The part of van Leuven-Zwart's model concerning shifts called 'modulations' uses the generalization-versus-specification continuum, which is of a semantic kind. Torop's model, instead, uses the self-versusother continuum, which is of a culture-oriented kind. The two continua are not mutually exclusive but rather complementary to each other; this is because they consider shifts from two different points of view - semantic and cultural respectively - both of which are highly productive. If we use both models simultaneously, we must also consider the middle part of either continuum: not only semantic generalization and semantic specification, but also neutral rendering; not only cultural appropriation and cultural acknowledgment, but also standardization. For example, in a translation from Russian to Italian, 'balalaika' might be rendered as 'balalaika' (cultural acknowledgment; neutral semantic rendering), or might be rendered as 'mandolin' (cultural appropriation + neutral semantic rendering), but it might also be rendered as 'a musical instrument' (semantic generalization + missing cultural acknowledgment), or as 'guitar' (cultural standardization) (94-5). As you can see from some of these examples, the seven categories are not per se mutually exclusive.

Table 1

\begin{tabular}{|c|c|c|c|c|c|}
\hline \multicolumn{6}{|c|}{ Text shifts: consequences on reception } \\
\hline & $\begin{array}{l}\text { Location } \\
\text { method }\end{array}$ & Shift concerns & Modulation & $\begin{array}{l}\text { Consequence } \\
\text { concerns }\end{array}$ & $\begin{array}{c}\text { Involved } \\
\text { relationship }\end{array}$ \\
\hline \multicolumn{6}{|c|}{ 1. Culture-specific } \\
\hline 1.1 & specific & $\begin{array}{l}\text { punctuation, } \\
\text { metrics, rhyme, } \\
\text { syntax }\end{array}$ & \multirow{5}{*}{$\begin{array}{c}\text { appropriation / } \\
\text { acknowledgement / } \\
\text { missing acknowledge- } \\
\text { ment (calque or standar- } \\
\text { dization) }\end{array}$} & $\begin{array}{l}\text { microtext } \\
\text { recitative } \\
\text { poetics }\end{array}$ & reader-actualization \\
\hline 1.2 & specific & $\begin{array}{l}\text { functional words } \\
\text { intratexts, repeti- } \\
\text { tions }\end{array}$ & & $\begin{array}{c}\text { structural } \\
\text { microtext } \\
\text { poetics } \\
\end{array}$ & reader-text structure \\
\hline 1.3 & specific & $\begin{array}{c}\text { expressive } \\
\text { domains }\end{array}$ & & $\begin{array}{c}\text { macrotext } \\
\text { poetics }\end{array}$ & $\begin{array}{c}\text { reader-author's } \\
\text { style }\end{array}$ \\
\hline 1.4 & specific & realia, intertexts & & $\begin{array}{l}\text { group psycholo- } \\
\text { gy }\end{array}$ & $\begin{array}{c}\text { reader-source } \\
\text { and/or target culture }\end{array}$ \\
\hline 1.5 & specific & deictics & & $\begin{array}{c}\text { microtext } \\
\text { expressive } \\
\text { poetics } \\
\text { individual } \\
\text { psychology } \\
\end{array}$ & $\begin{array}{l}\text { reader-inner narra- } \\
\text { tor (narrative); } \\
\text { reader-character } \\
\quad(\text { dialogue })\end{array}$ \\
\hline \multicolumn{6}{|c|}{ 2. non-culture-specific } \\
\hline 2.1 & specific & $\begin{array}{l}\text { lexical specifici- } \\
\text { ty, registers, } \\
\text { words/terms }\end{array}$ & $\begin{array}{c}\text { specification } \\
\text { generalization } \\
\text { neuter rendering }\end{array}$ & $\begin{array}{c}\text { microtext } \\
\text { expressive } \\
\text { poetics } \\
\text { individual } \\
\text { psychology } \\
\end{array}$ & $\begin{array}{l}\text { reader-text style } \\
\text { (narrative) } \\
\text { reader-character } \\
\text { (dialogue) }\end{array}$ \\
\hline 2.2 & generic & $\begin{array}{r}\text { non-ternary oppos } \\
\text { radical changes o } \\
\text { notior }\end{array}$ & $\begin{array}{l}\text { ons: omissions, additions, } \\
\text { ense, grammatical shifts, } \\
\text { ords, lexicon }\end{array}$ & $\begin{array}{l}\text { text denotative- } \\
\text { ness }\end{array}$ & $\begin{array}{l}\text { reader-denotative } \\
\text { content of the text }\end{array}$ \\
\hline
\end{tabular}

This table is a revised version of the table in Osimo (2004:97). The term 'microtext' refers to the single text involved in a given 
comparative analysis, whereas 'macrotext' refers to a group of texts of which the microtext is part (all the works by that same author or institution, for example). 'Intertexts' are intertextual references, whereas 'intratexts' are references to other parts of the same text; intratexts are cardinal to the text's cohesion. In the seventh group (2.2) we find both van LeuvenZwart's radical changes of sense, omissions and additions, and those grammatical shifts with unpredictable spin-offs (such as changes of grammatical genre, or tense: think of the Italian passato remoto and passato prossimo both used to translate an English simple past). This group of shifts may be the weakest from a theoretical point of view, since all the 'other' shifts (those that do not fit into any other group) fall into it. As the aim of the model is to systematize shifts from the point of view of their effect on the reader's perception of the text (i.e. meaning), the seventh group is probably the least fortunate, because it does not suggest any specific effect, leaving it to a case-by-case assessment. However, as everybody who has to do with translations knows, such shifts do occur. Unfortunately, not all translation choices are modulations: there are also changes that defy logic; that are, from the point of view of the critic or editor, 'delusionary'. As in a delusion, it is difficult, if not impossible, to ascribe such shifts to any logic. They are sometimes called 'misunderstandings', 'mistranslations', 'mistakes'. Here, meaning goes adrift. For this reason the seventh category (2.2) represents a weakness, which is the direct consequence of a weakness in our (translators') practice.

Let us now examine the single categories. Excerpts from the first book of the Bible (In the beginning, or Genesis) in the original Hebrew and in English will be used by way of illustration.

\subsection{Cultural shifts (relationship shifts)}

This category includes all shifts regarding the relationship between the source culture, the receiving culture, and other cultures. The notion of 'culture' is meant here in a broad sense, i.e. both as a national culture and as an individual culture (an author's style, for example), with all the intermediate possibilities as regards group culture. By 'culture' I mean a group of people having the same cultural implicits, i.e. taking for granted the same things when they speak or write (Osimo 2001). A similar, and useful, view can be seen in Agar, who writes:

Like a translation, culture is relational. Like a translation, culture links a source languaculture, LC2, to a target languaculture, LC1. Like a translation, it makes no sense to talk about the culture of $\mathrm{X}$ without saying the culture of $X$ for $Y$. Whenever we see the term culture, we need to ask, of whom and for whom? Culture names the translation required, given contact between a particular source and a particular target. (2006:5) 
Cultural shifts are, therefore, shifts concerning the differences in the perspective of a relationship.

\subsubsection{Punctuation, syntax, rhyme, metre}

The changes included in this category are features which have consequences for the reader's actualization of the text, whether the text is read out loud or not. In the latter case a sort of 'mental reading' occurs, during which the subject unconsciously imagines all the practical, 'musical' consequences of reading. Such features include speed, pauses, rhythm (where punctuation plays a fundamental role), the way something is pronounced or read, right or left dislocations, split sentences, and other sentence-structure devices governing the rheme-theme dynamics (where the fundamental role is played by syntax).

The use of such features is often culture-specific (for example, in the source language commas may be compulsory in instances where they are forbidden in the target language); nevertheless, every culture has its way of phrasing similar expressive traits. In the following example, the original has no punctuation (save for the equivalent of a full stop at the end); in square brackets, a version is given trying to produce as few shifts as possible. Bible 1949 is one of the most widespread versions, with punctuation emphasized:

(1) vay'varekh otam Elohiym leamor p'ru ur'vu umil'u ethamayim bayamim v'ha"okh yirev baaretz:

[and blessed them Elohiym to say fructify and increase and fill the waters in the seas and let fowl increase on the land:]

And God gave them his blessing, saying, 'Be fertile and have increase, and fill the waters in the seas, and the fowl let multiply in the earth': (Bible 1949)

Some of the pauses suggested by commas are inevitable in any case for the reader of the English version; others may be a question of personal taste and personality. Due to the number of pauses 'written' into the right-hand column version the reader will read more slowly, stopping where the translator has inserted commas.

Old Hebrew often has no punctuation. One might wonder, then, what the point of this example is. In my opinion, the fact that the source culture has no punctuation is not relevant. Since the target culture does have punctuation, the point is - as usual - to evaluate different possible translation strategies. A translator (an editor, a publisher) can decide to provide a text without punctuation (for philological reasons), or a text with punctuation (for readability reasons). The point then is: what are the differences in the reception of the text in the two versions? 
In the following example we have a rhyme (in prose) in the original. The Hebrew has the word 'tohu' (shapelessness) rhyming with 'vohu' (emptiness), which unconsciously strengthens the meaning of the sentence. The rhyme should be preserved in translation, since it makes the word-order easier to remember. In fact, in Modern Hebrew, 'tohu vavohu' is a common collocation meaning 'confusion'. As in the previous example, the middle column has as few changes as possible, while the right-hand column contains a widespread version:

(2) v'haarez hay'ta tohu vavohu [and the land was shapelessness and emptiness]

The earth was formless and void (Bible 1971)

For the time being I do not consider other kinds of shift (for example, the name $\rightarrow$ adjective grammatical-category change) implied in such a version. A single word shift can refer to more than one category.

The last example for this category (oral actualization) concerns word order, another device altering the mode in which messages are decoded. In the following excerpt, the first version has the topic stated first, whereas the second begins with the comment.

(3) vay'varekh otam Elohiym; VOS

[and blessed them Elohiym; VOS]

And God gave them his blessing (Bible 1949); SVO

This trait is also culture-specific. Depending on language pairs, a sentence with such a shift in structure is often perceived as more (or less) 'poetic' or 'literary'.

\subsubsection{Functional words}

These are particular words whose semantic meaning is not necessarily important, but that are spread throughout the text to physically link distant text areas so as to create intratextual references. These features have consequences for the reader's reception of the text's structure. Because of their cohesive function they are also called 'bridge words'. Shifts in these words have consequences for the perception of the structure of the text as a whole.

(4) qol remeš adamah 1.25; eyin la"avod et-haadamah 2.5; v'Qain haiah “oved adamah 4.2; zoaqim eli minhaadamah 4.10

[every creeping of the ground; the man is not there to work the ground; and Qain was a worker of the ground; is crying toward me from the ground]

and every living thing moving on the face of the earth; there was no one to farm the land; but Cain was a farmer; is crying to me from the earth (Bible 1949). 
In these occurrences, taken from four different passages of the book, the same word 'adamah' is translated in different ways. So the intratextual links are lost. Omitting the repetition has consequences for the text's structure, for its roundness. Of course, in judging such shifts one has to take into account the anisomorphism of languages and the plausible impossibility to use the same translatant for all occurrences.

\subsubsection{Expressive domains}

These are features that characterize the specific style traits of the macrotext. The difference between expressive domains and functional words is that expressive domains are selected by the author in a paradigmatic sense among different expressive possibilities for the same referential meaning. By contrast, functional words are words of any kind, even sounds (as in Chekhov, where one such functional word was a noise in the courtyard), that are placed by the author in strategically significant places of the text to create a network of topical references among different areas of the text. Shifts in expressive domains affect the reader's reception of the author's style (an institution can also be considered an 'author' in this sense). These are words, idioms, phrases, grammatical forms that do not have a particular significance in themselves but are typical of an author's expressiveness. In the following examples, from In the beginning 7, 11 and 12, the Hebrew verb la'asot (to make) is used repeatedly, while in the English version we find different solutions.

(5) aya"as Elohiym et-haraqiya"; “etz p'ri “oseh p'ri l'miyno; v"'etz "iseh-p'riy ašer; "aleh t'enah vaya"'su lahem [and made Elohiym the expanse 7; the fruit-tree make fruit of the kind 11; and tree making fruit in which 12] God made the expanse; fruit trees on the earth bearing fruit after their kind; trees bearing fruit with (Bible 1971)

Here, the author's style implies the use of the same verb in different parts of the text; this can be considered a keyword in a text about making, creation. The use of different translatants for the same root produces a shift of reception as far as the author's style is concerned. Milan Kundera (1993:131) has noticed with great disappointment that translators often tend to produce such shifts with basic everyday verbs such as do, make, be, have, and their most obvious translatants in different languages. 


\subsubsection{Intertextuality and realia}

If the words in a certain category can be shifted then it is also possible to identify them by means of a place, a people, a group or a text shared by a group of people (by a 'culture' as defined in 1.1). From this point of view, a reference to a different text and a reference to a different culture are very similar to each other, since from a semiotic point of view a culture is a text. Since every culture has its own implicit values, sometimes emerging like iceberg tips from people's discourses in the form of words, translation strategies have to make a choice in this respect: should these iceberg tips be 'transferred' as much as possible as they are, preserving the reference to a given culture (often the source culture), or should they be adapted to the receiving culture?

This is the reason why I call the consequences of such shifts 'group psychology': they have consequences for the reader's reception of the source and/or target culture and for the way a text relates to other cultures. The manipulation of such expressions impacts the relationship between cultural systems, i.e. the group psychology of elements belonging to the text's culture. In this example the action of swearing is described, using a particular verb containing the root of the number seven:

(6) v'"atah hišav"'ah liy belohiym henah [and now swear seven times to me by God here]

Now, then, give me your oath, in the name of God (Bible 1949)

The verb hašva"ah derives from the root of number seven šiv"ah, and has the meaning of 'swearing seven times', i.e. it is stronger because the number seven in Jewish culture symbolically means 'great quantity'. The presence of the number seven can thus be connected to its overall presence in Jewish culture and in the Bible. The translation 'give me your oath' preserves the denotative meaning of the action without its cultural contextual description.

\subsubsection{Deictics}

Since deictics describe time and place situations from the utterer's point of view, they refer to the personal mental attitude of the utterer toward a given situation. For this reason, I consider these features as shifters of individual psychology. Since the utterer is the narrator or a character, shifting deictics impacts the reader's reception of the inner narrator's or the character's psychology. In this passage of In the beginning a deictic is referred to Elohiym (God):

(7) vayare Elohiym et-kol-ašer “asa v'hineh-tov m'od: 
[And saw Elohiym all what he had made and here it is very good.]

And God saw everything which he had made and it was very good (Bible 1949).

The deictic 'hineh' brings creator and reader close together. Since the narrator says 'here' after a reference to Elohiym, preserving the reference in translation will give the reader the impression that the narrator is near the things God created. If, on the other hand, the 'here' is omitted, the reader will lose this impression and experience Elohiym as a far-away entity.

The translation of deictics depends on the general view of translation: according to some translators, if "A translation should read like an original work" (Savory 1968:50) then deictics can be either omitted or changed to match the new situation created by translation. Going to extremes, if, for example, an American text reads 'this is my people', a hypothetic translation into Italian should read 'quello è il loro popolo', or 'quello è il popolo Americano'. In this case, the deictic element is preserved (not omitted like in the previous example taken from In the beginning), but shifted to maintain the reference to the same entity (which, due to geographic transfer, is no longer 'here' but 'there').

\subsection{Semantic shifts}

This category includes shifts that are not culture-specific, concerning instead the semantic field of the words used in the pair of texts.

\subsubsection{Lexical specificity, words $\leftrightarrow$ terms, registers}

This category of shifts moves along the specification-generalization continuum, therefore including all transfers from a common word to a specific term and vice versa. Registers also come into play because standard registers can be considered more general than specific registers (both high registers and low registers). For this reason I believe that the consequence of such shifts has an impact on the reception of the text's style and expressivity and - if the shifts concern the utterance or the description of a character the reader's psychological perception of a given character. In a version of the following passage, a common Hebrew word, 'ruakh', meaning specifically 'wind', is translated with a more generic, abstract term, 'spirit':

(7) v'ruakh elohim m'rakhepet “al-p'ney hamayim [and wind of Elohiym hovers over the face of the waters] and the Spirit of God fluttering on the face of the waters (1863).

We can consider this as a change of register ('wind' $\rightarrow$ 'spirit') in the direction of generalization; it introduces a new notion (spirit) that is abstract. 
Nida (1964:106-7) gives a detailed explanation of the broad semantic field of 'spirit', locating eleven different meanings for the word. A standard, plain reading of the text gives only the technical, concrete idea of simple wind as a weather element. This is a case of generalization.

\subsubsection{Omissions, additions, radical changes of sense, grammatical shifts, notion words}

As stated in the introduction, this category includes denotative shifts whose impact is predictable only on a case-by-case basis. The consequences of omitting a word will depend on the meaning of the omitted word; the same goes for added words, radically changed semantic values and so on. I call these shifts 'delusionary' both because we cannot reconstruct the translator's logic behind the shift, and because the reader's logic is also led to go astray. Sometimes a translator introduces such a shift on purpose to compensate for some other unwanted shift in other parts of the text; if the editor is not aware of this, the consequences can be marked. These features affect the reader's reception of the text's denotative content. In the following example of addition, in the right-column version two words are added to the word-by-word version in the middle column:

(8) v'khošeh “al-p'ney t'hom: [and darkness on the face of the deep.] and darkness covered the deep water (Bible 1998).

Omissions are generalizing, whereas additions are usually specifying. In this sense this category shares some of its traits with the previous one (generalization, specification). A translator tends to add where s/he thinks that something in the prototext is not clear enough, and feels the need to add one or more words. With such an approach the reader is viewed as less smart than the translator and the former's chance to interpret is guided, directed, restricted. While in some cases the addition may be motivated by grammatical considerations (like, in our example, the insertion of a - noncompulsory - verb), in other cases the addition is totally unjustified, as in the case of 'water'. The kind of mediation implied in such an addition is neither linguistic nor cultural - it is the need to compel the decoding of the text in a given direction. Here Eco's notion of 'overcoding' can be useful (1984:14).

\section{A shift-based view of meaning}

For us, both as linguists and as ordinary word-users, the meaning of any linguistic sign is its translation into some further, alternative sign, especially a sign "in which it is more fully developed", as Peirce, the deepest inquirer into the essence of signs, insistently stated (Jakobson 1959: 261). 
If we agree with such a definition, then in order to understand meaning we must inquire into that 'development'. Development in translation can take different directions. Jakobson himself indicates three such directions: intersemiotic, interlingual and intralingual. If such a triad is taken not as complementary, but as supplementary (i.e. in each translation process the three types of translation occur simultaneously), we may delineate new fields of study. Moreover, the view of meaning emerging from such a model has several prominent characteristics:

- the principle of meaning as translation is taken literally from a practical point of view and, on the basis of empirical comparisons between texts and their observed interlingual translations, three macrocategories of shifts emerge: cultural shifts, semantic non-culturespecific shifts, and radical changes of sense;

- $\quad$ cultural shifts can be further specified;

- $\quad$ since the notion of 'culture' does not necessarily coincide with that of 'national culture', translation shifts can be described in these terms also within one language, i.e. in intralingual translation;

- culture-specific shifts cause changes that, besides being semantic, also involve cultural identities (of the sender, of the receiver, of a superordered setting);

- potential shifts in meaning are located along two continua: self $\leftrightarrow$ other (or one's own $\leftrightarrow$ alien) for culture-specific shifts, and generalization $\leftrightarrow$ specification;

- $\quad$ since communication acts often involve three cultures (the sender's, the receiver's, and a superordered culture), the self-other axis must evolve into a triad, its three points being the sender's culture, the receiver's culture, and a standard superordered culture;

- $\quad$ certain semantic shifts defy categorization because their motivation defies explanation; they are neither culture-specific shifts nor purely semantic modulations; they belong to the category of 'delusions' or ideologically compelling shifts.

If we accept this model then we can see meaning shift in three possible directions: 1 . the acknowledgement, the negation, or the negligence of the cultural identity of the text ("I understand what is said, but I do not understand/I do not want to recognize who has said it, what the human potential of the text is."); 2. the over-translation (exaggeration), under-translation (understatement) of (or proper consideration for) the semantic/syntactic/pragmatic meaning (Wills 1996) ("I understate/overstate/restate what has been said."); $>3$. 'delusion', unexplainable shift, ideological manipulation that is not quantifiable ("I take what has been said as a pretext to say what I want to say.").

Peirce, speaking about thought-signs, finds an analogy between semantic shifts and logical steps, which helps to understand the last category 
('delusions'). "There is no exception, therefore, to the law that every thought-sign is translated or interpreted in a subsequent one, unless it be that all thought comes to an abrupt and final end in death" (Peirce 5:284). If translation processes are in fact verbal explicitations of thought processes, no surprise, then, if we have (so to speak) 'delusionary' translations. (this, indeed, is not intended to imply that only psychotic translators can produce 'delusionary' shifts: here, 'delusion' is meant as a metaphor.) This also means that self-communication, understanding, and the verbalization of thought can be considered translation processes as well, following the same categories of shifts.

A translation-based view of meaning must account for the fact that, as with thought, general meaning can never be ultimately defined; one can always continue to think and interpret. "Peirce denoted the translational processuality, steadily generating new thought, in the figurative phrases of a proverb: "The life we lead is a life of signs. Sign under Sign endlessly", (Gorlée 2007:218). The only limit to final rethinking (and shifting) is a physical limit: it is the so-called 'final interpretant', which coincides with death, or with the end of a translation (the interlingual translation is physically given to the customer), or with the 'final draft' (the last one prior to printing) of a text.

A new theory of meaning cannot do without the concept of transformation; it explains how the modal resources provide users of the resource with the ability to reshape the (form of the) resources at all times in relation to the needs of the interests of the sign-maker. Transformation needs to be complemented by the concept of transduction [...] transduction accounts for the shift of 'semiotic material' - for want of a better word - across modes (Kress 2003:36).

Having been merely one of the many branches of lexical linguistics until fifty years ago, translation theory now proposes itself as the kingpin of semiotics. The notion of 'translation' is central to redefining the new frontiers of meaning and signification. Lotman used to speak of the border as the place where two cultures meet and compare, and of translation as the culture of the border, as the culture of awareness of the differences between different spheres. This awareness is described by Agar as follows: "culture becomes visible only when an outsider encounters it, and what becomes visible depends on the LC1 of the outsider" (2006:10). Following Agar, we can say that meaning becomes visible only when a translator encounters it, and what becomes visible depends on the linguistic and cultural background of the translator. Meaning is seen better on the border. 


\section{Bibliography}

Berkeley, George (1710-1734). A Treatise Concerning the Principles of Human Knowledge, Oxford: Oxford University Press, 1998.

Bible (1863). The Holy Bible, Consisting of the Old and New Covenants; Translated according to the Letter and Idioms of the Original Languages [by Robert Young]. Edinburgh: George Adam Young \& Co.

Agar, Michael (2006). "Culture: Can You Take It Anywhere?". International Journal of Qualitative Methods, 5(2):1-12.

Bible (1917). The Holy Scriptures According to the Masoretic Text. Philadelphia: Jewish Publication Society of America.

Bible (1949). The Bible in Basic English. Cambridge: University Press, in association with Evans Brothers.

Bible (1971). New American standard Bible. La Habra (California), Foundation Press Publications, publisher for the Lockman Foundation.

Bible (1998). Bible. English. God's Word.

Cornejo, Carlos (2007). "The Locus of Subjectivity in Cultural Studies". Culture \& Psychology, $13: 243-256$.

Eco, Umberto (1984). The Role of the Reader. Explorations in the Semiotics of Texts. Bloomington: Indiana University Press.

Eco, Umberto (1992). Interpretation and Overinterpretation. Cambridge: Cambridge University Press.

Gorlée, Dinda L. (2007). "Broken signs: The architectonic translation of Peirce's fragments". Semiotica, Berlin: De Gruyter, 164, 1/4: 209-287.

Jakobson, Roman (1959). "On Linguistic Aspects of Translation". R. A. Brower (ed) (1959). On Translation, Cambridge: Harvard University Press and in 1971, 260-266.

Jakobson, Roman (1971). Selected Writings, 2, Word and Language, Den Haag, Paris: Mouton.

Jakobson, Roman (1975). "A Few Remarks on Peirce, Pathfinder in the Science of Language". Modern Language Notes, 92, 1977, and in 1985, 248-253.

Jakobson, Roman (1985). Selected Writings, 7, Contributions to Comparative Mythology. Studies in Linguistics and Philology, 1972-1982. Berlin, New York, Amsterdam: Mouton.

Kress, Gunther (2003). Literacy in the New Media Age. London and New York: Routledge.

Kundera, Milan (1993). Les testaments trahis. Paris: Gallimard.

Lotman, Yury (1990). Universe of mind. A Semiotic Theory of Culture. Bloomington: Indiana University Press.

Lûdskanov, Aleksandr (2008). Un approccio semiotico alla traduzione. Dalla prospettiva informatica alla scienza traduttiva (ed. B. Osimo). Milano: Hoepli. Original Bulgarian edition Sofia 1967.

Luhrmann, Tanya Marie (2006). "Subjectivity". Anthropological Theory, 6:345-361.

Nida, Eugene (1964). Toward a science of translation. Leiden: Brill.

Osimo, Bruno (2002). "Traduzione della cultura”, in G. P. Piretto (ed) Parole, immagini, suoni di Russia. Saggi di metodologia della cultura. Milano: Unicopli.

Osimo, Bruno (2004). Traduzione e qualità. La valutazione in ambito accademico e professionale. Milano: Hoepli.

Peirce, Charles Sanders (1866-1913). The Collected Papers of Charles Sanders Peirce, vol. 1-6. C. Hartshorne and P. Weiss (eds) (1931-1935). Vol. 7-8. A. W. Burks (ed) (1958), Cambridge (Massachusetts): Harvard University Press.

Popovič, Anton (2007). La scienza della traduzione. Aspetti metodologici. La comunicazione traduttiva. (ed. B. Osimo). Milano: Hoepli. Original Slovak edition Nitra 1975.

Pym, Antony (2007). "Natural and directional equivalence in theories of translation", Target. 19(2): 271-294.

Savory, Theodore Horace (1968). The Art of Translation. A New and Enlarged Edition. London: Cape.

Shannon, Claude Elwood \& Weaver, Warren (1949). The mathematical theory of communication. Urbana IL: University of Illinois Press.

Torop, Peeter (2000). La traduzione totale. Total'nyj perevod. (ed. B. Osimo). Modena: Guaraldi Logos. Original Russian edition Tartu 1995.

Torop, Peeter (2001). "The Possible Fate of the Semiotics of Translation". Interlitteraria, 6:46-62.

Van Leuven-Zwart, Kitty (1989-1990). "Translation and original. Similarities and dissimilarities". Target, $1: 2$ and 2:1. 
Wills, Wolfram (1996). Knowledge and Skills in Translation Behaviour. Amsterdam: Benjamins. 